Check for updates

The BMJ

Cite this as: BMJ 2021;372:n146 http://dx.doi.org/10.1136/bmj.n146 Published: 15 January 2021

\section{Covid-19: Doctors' leaders call for revised PPE guidance to reflect new variants}

\section{Gareth lacobucci}

Medical leaders have urged Public Health England to strengthen its guidance on personal protective equipment (PPE) to reflect the more transmissible forms of SARS-CoV-2 that healthcare staff are being exposed to.

Current guidance says that higher grade $\mathrm{FFP}_{3}$ masks should be provided to staff who are involved in aerosol generating procedures, but other staff looking after patients with covid-19 are only required to wear fluid resistant surgical masks.

In a letter to Public Health England sent on 13 January, BMA council chair Chaand Nagpaul said that, in light of the identification of the new variant of SARS-CoV-2, increased spread of the virus, and growing evidence of aerosol transmission, Public Health England should review its recommendations on PPE usage "so that a more precautionary approach is adopted to the provision of respiratory protective equipment (RPE) to ensure staff are protected from aerosol transmission."

He wrote: “There are significant and growing concerns about the role of aerosol transmission of covid-19 in healthcare settings, and the need for wider use of RPE (for example, $\mathrm{FFP}_{3}$ respirators) outside of those procedures designated as aerosol generating. We are therefore calling on [Public Health England] to support the wider use of RPE in other high risk settings across primary and secondary care.”

Nagpaul mentioned evidence indicating lower infection rates among staff in areas where higher grade RPE is currently recommended. ${ }^{1} \mathrm{He}$ also pointed out that the World Health Organization modified its guidance in December to advise that where respirators were available, they should be considered for wider use. ${ }^{2}$

The Doctors' Association UK also called on Public Health England to review its guidelines on PPE for healthcare workers. The organisation said that there were 44000 NHS staff currently absent because of covid-19, with many becoming unwell because of the new, more transmissible variant.

Katie Sanderson, spokesperson for the association, said, "Healthcare workers in the UK continue to become infected with covid-19 at work at rates that could be mitigated by access to better personal protective equipment."

Jenny Vaughan, vice chair of the Doctors' Association UK, said that the organisation was "calling for a full review of the PPE guidelines including wider access to $\mathrm{FFP}_{3}$ masks. So many NHS staff are getting sick because of the new, more transmissible variant. The covid-19 virus has changed, and yet the same guidelines we introduced in March have not been updated."

Ensuring greater protection was especially vital for staff who were more at risk from covid-19, such as doctors from an ethnic minority background, the medical bodies said.

The interventions follow a similar call from Fresh Air NHS, a group of frontline healthcare workers who recently wrote an open letter to UK politicians urging them to recognise the importance of airborne transmission of SARS CoV-2 and to ensure that measures were in place to protect staff and patients. ${ }^{3}$

Yvonne Doyle, medical director at Public Health England, "NHS staff are under immense pressures and their safety has always been our highest priority. The NHS Infection Prevention Control group has reviewed the latest evidence and has advised that PPE should continue to be worn as laid out in the with $\mathrm{FFP}_{3}$ masks required for staff undertaking clinical aerosol generating procedures. This is supported by [the World Health Organization]. Emerging evidence and data on variant strains and transmission will be continually monitored and reviewed."

Shields A, Faustini SE, Perez-Toledo M, etal. SARS-CoV-2 seroprevalence and asymptomatic viral carriage in healthcare workers: a cross-sectional study. Thorax 2020;75:1089-94.

doi: 10.1136/thoraxjnl-2020-215414. pmid: 32917840

2 WHO. Advice on the use of masks in the community, during home care and in healthcare settings in the context of the novel coronavirus outbreak 1 Dec. 2020, https://www.who.int/publications-detail-redirect/advice-onthe-use-of-masks-in-the-community-during-home-care-and-in-healthcaresettings-in-the-context-of-the-novel-coronavirus-(2019-ncov)-outbreak.

3 Wise J. Covid-19: Doctors and nurses demand better PPE for wider range of procedures. BM/2021;372:n30. doi: 10.1136/bmj.n30 pmid: 33408072 current [infection prevention and control] guidance, 